\title{
Migração e rendimentos no Brasil: análise dos fatores associados no período intercensitário 2000-2010
}

LUIZ CARLOS DAY GAMA I

e ANA FLÁVIA MACHADO II

\section{Introdução}

$\mathrm{D}$ IFERENCIAIS de rendimentos entre migrantes e não migrantes são analisados no Brasil e no resto do mundo. As profundas transformações pelas quais o Brasil passou nos últimos anos - especialmente a redução na desigualdade de renda - podem ter modificado o processo migratório e também a decisão de migrar.

Há, fundamentalmente, três tipos de migração: migração stricto sensu, em uma única etapa; migração de retorno e migração progressiva. Por limitações da base de dados, este artigo considera os dois primeiros. Tanto a migração de única etapa como a repetida (retorno à cidade natal) podem contribuir para o aumento da convergência de renda em uma região, como também para o contrário. Assumindo a hipótese de que os migrantes são pessoas de habilidades diferenciadas (ainda que seja a ousadia), a região de origem, em princípio, estaria sofrendo um braindrain (perdendo trabalhadores com melhores atributos) quando esses indivíduos migram. Porém, como enfatizam Mayr e Peri (2008), se políticas corretas de incentivos de retorno forem definidas, esse braindrain pode ser transformado em um braingain, ou seja, os indivíduos retornariam com maior conhecimento, contribuindo para melhoria da região.

Este artigo tem, assim, por propósito analisar fatores associados aos diferenciais de rendimentos entre migrantes, migrantes de retorno e não migrantes no Brasil, no período intercensitário de 2000 a 2010. Além desta parte introdutória, o artigo é dividido em quatro seções. A segunda introduz os modelos teóricos que explicam as decisões por migrar, seguido de uma revisão sobre os fatos estilizados referentes à migração. Na terceira, é apresentada a metodologia utilizada compatível aos objetivos propostos. A quarta traz resultados das estatísticas descritivas e das estimações. Na quinta e última seção, são apresentadas as considerações finais. 


\section{Arcabouços teóricos e empíricos sobre as decisões por migrar}

O tema migração é recorrente nos estudos sobre mercado de trabalho. Um dos estudos pioneiros é o de Sjaastad (1962), o qual afirma que um trabalhador ao migrar enfrenta custos monetários e não monetários, no intuito de maximizar o valor de sua utilidade no ciclo de vida. $\mathrm{O}$ autor percebe o processo migratório do mesmo modo que a formação educacional, ou seja, um investimento por parte do indivíduo. Com isso, defende que os migrantes são positivamente selecionados com relação às características observáveis. Para Dustmann e Glitz (2011), um indivíduo migra por dois motivos: quando é forçado, seja por causas naturais, políticas e/ou religiosas, ou quando acredita que as perspectivas econômicas são mais favoráveis em outra região.

Borjas (1987) e Dustmann e Glitz (2011) argumentam que os migrantes são positivamente selecionados com relação às características não mensuráveis. Em outras palavras, apresentam, em média, melhores características não observáveis $^{1}$ que os não migrantes e, por isso, contam com maior capacidade para arcar com os custos de migrar, o que tende a contribuir para um aumento de produtividade no local de destino e, consequentemente, para uma redução no local de origem. Freguglia (2007) afirma que os migrantes não são uma amostra aleatória da população nas localidades de origem e aumentos salariais, após a migração, podem refletir habilidades não observadas que são vivenciadas na região de destino, evidenciadas em aumento de sua produtividade. O impacto sobre a região de destino dependeria, assim, dos diferenciais de habilidades entre os migrantes e os não migrantes.

Fatores geográficos ainda são pouco abordados pela literatura internacional no estudo da migração. Porém, em um país com dimensões continentais como o Brasil, esse fator não pode ser desconsiderado. Para alguns autores, como Sahota (1968) e Cooper (1994), o diferencial de rendimentos entre regiões é uma das principais causas que levam um indivíduo a migrar. Rodriguez-Pose e Tselios (2010) sugerem a importância de analisar a influência das disparidades regionais sobre a migração, pois algumas regiões podem ser mais receptivas aos migrantes. Esse conjunto de fatores, aos quais os autores dão o nome de externalidades regionais, pode levar indivíduos com níveis educacionais semelhantes, empregados em trabalhos semelhantes, a receberem remunerações distintas, quando em áreas diferentes.

Ademais, no que diz respeito à migração de retorno, migra-se para ampliar a formação de competências e depois retorna-se à cidade natal, por laços afetivos, como por maior valorização de experiência e de hábitos adquiridos. Outro motivo pode, também, levar um indivíduo a realizar a migração de retorno: após migrar, o trabalhador pode chegar à conclusão de que a mudança foi um erro e, por isso, decidir voltar à região de origem (Rooth; Saarela, 2007, p.91). Um baixo nível de informação sobre a região de destino e, sobretudo, a conjuntura socioeconômica desfavorável pode conduzi-lo ao retorno. 
No Brasil, Cunha e Baeninger (2005), ao compararem os anos 1970 com os 1990, observaram que houve um incremento da migração de retorno da ordem de $221 \%$ no período. Além disso, o Nordeste foi a região de maior recepção e, no passado, era a de maior fluxo de emigração. Já Cunha (2006) tentou identificar como estava a situação migratória brasileira nos primeiros anos do século XXI, comparando-se à década anterior. O autor afirma que cerca de $30 \%$ dos movimentos migratórios registrados no país, entre 1999 e 2004, são de migração de retorno, e, analisando apenas o Nordeste, esse percentual alcança $51 \%$.

Siqueira, Magalhães e Silveira Neto (2009) utilizam dados do Censo (2000) a fim de analisar a migração de retorno e progressiva no Brasil entre $1995 / 2000$. Mostram que quase $18 \%$ do total de migrantes eram de retorno e $13 \%$ eram migrantes progressivos. Concluem que jovens e adultos são mais propensos a migrar em todas as categorias e indivíduos mais escolarizados são menos propensos a realizar a migração de retorno, a de única etapa ou progressiva.

Como visto acima, vários fatores afetam as decisões de migração dos indivíduos. Além disso, um conjunto de características pessoais e regionais influencia os ganhos dos trabalhadores. Portanto, saber, por exemplo, como está a conjuntura do mercado de trabalho regional é de suma importância para se entender como são gerados os diferenciais de rendimentos entre migrantes e não migrantes.

\section{Metodologia}

Alguns estudos defendem que a escolha por migrar pode ser uma das muitas decisões que se toma ao longo da vida. Dahl (2002) argumenta que se os trabalhadores escolhem migrar para um estado baseado em vantagens comparativas, os retornos à educação podem estar enviesados, devido à autosseleção dos migrantes. Por essa razão, estimamos um modelo econométrico que busca corrigir esse viés.

\section{Modelo econométrico}

Como se pretende analisar os fatores associados ao diferencial de rendimentos, recorre-se ao logaritmo do rendimento mensal do trabalhador no trabalho principal. O viés de seleção é corrigido através de uma extensão da Correção de Heckman.

Assume-se, inicialmente, que as variáveis apresentam uma relação linear. A forma funcional pode ser definida da seguinte maneira:

$$
\operatorname{logRend}_{i t}=\beta_{0}+\beta_{1} X_{i t}+\mu_{i t}
$$

onde $\log$ Rend $_{i t}$ é o logaritmo do rendimento mensal do indivíduo, $X_{i t}$ é um vetor de características individuais, familiares e regionais (consideradas exógenas), como educação, se vive ou não em área metropolitana etc., e, $m_{t}$ é o termo de erro.

Como variáveis categóricas, são utilizados sexo, nível de instrução, entre outras, e, a mais importante para este artigo, se o indivíduo é ou não migrante 
de única etapa ou progressivo, ou migrante de retorno. Com a inclusão dessa dummy de migração, a especificação do modelo é a seguinte:

$$
\log \text { Rend }_{i t}=\gamma_{0}+\gamma_{1} X_{i t}+\gamma_{2} M_{i t}+\omega_{i t}
$$

Assim, espera-se que, devido ao viés de seleção, o termo de erro seja correlacionado com a dummy de migração, ou seja, que existam características não observadas que afetem tanto os salários quanto a probabilidade de migrar $\left(\operatorname{Cov}\left[M_{i}, \omega_{i}\right] \neq 0\right)$.

A equação (2) não pode ser estimada diretamente por Mínimos Quadrados Ordinários (MQO), pois $M$ é uma variável relacionada ao logaritmo do rendimento, ou seja, a decisão por migrar é tomada baseada nos ganhos esperados. Como $M$ depende de várias características observáveis e não observáveis, assume-se:

$$
M_{k i}^{*}=\delta_{k} \mathrm{Z}_{\mathrm{ki}}+\varepsilon_{\mathrm{ki}} \quad(k=1,2 ; i=1,2, \ldots, N)
$$

onde $Z$ engloba um conjunto de características observáveis $k$ do indivíduo $i$. Se $M_{k i}^{*}>0$, o indivíduo migra. Dessa maneira, é necessária uma metodologia que dê conta do viés de seleção. Para contornar tal problema, recorre-se à chamada Correção de Heckman (1979).

\section{Modelo Probit multinomial}

O Modelo Probit Multinomial (MPN) possui propriedades teóricas que o tornam atrativo, sendo aplicado no primeiro estágio da correção. Portanto, no primeiro estagio, é estimada a equação (3), de forma que:

$$
P_{r}(M=1 \text { ou } 2)=P_{r}\left(M_{k}^{*}>0\right)
$$

A razão inversa de Mills $\left(\lambda_{i}\right)$ é gerada após a estimativa da equação (3), através da fórmula demonstrada em (5):

$$
\lambda_{i}=\frac{\phi\left(Z_{k i}\right)}{1-\Phi\left(Z_{k i}\right)}=\frac{\phi\left(Z_{k i}\right)}{\Phi\left(-Z_{k i}\right)}
$$

onde $\phi$ é a função de densidade normal padrão e $\Phi$ é a função de distribuição normal padrão. $\lambda_{i}$ assume valores entre 0 e $\infty$. A razão inversa de Mills é incluída na equação (6):

$$
\operatorname{logRend}_{i t}=\alpha X_{i t}+\beta M_{i t}+\gamma \lambda_{i t}+z_{i t}
$$

onde é $\log R e n d$ o rendimento percebido no mês pelo indivíduo $i$ no ano $t, X$ é um conjunto de características individuais e regionais, $M$ é a dummy de migração, $\lambda_{i}$ é a razão inversa de Mills e $Z$ é o termo de erro.

A equação (6) pode ser estimada por MQO.

\section{Dados e variáveis}

A fonte de dados é a amostra do Censo Demográfico nos anos 2000 e 2010. Partindo-se da amostra do IBGE, selecionam-se indivíduos com idade entre 25 e 65 anos, ${ }^{2}$ por se encontrarem em idade ativa. Todos os valores nominais em 2000 foram corrigidos pelo Índice Nacional de Preços ao Consumidor 
(INPC) a preços de julho de 2010. Amarelos, indígenas e indivíduos que não declaram nenhuma cor foram excluídos, pois eram pouco representativos. Por fim, também não foram incluídos indivíduos cujo nível de instrução era indeterminado. Com isso, em 2000, a amostra é composta por 8.716.045 indivíduos, sendo 5.081.998 ocupados em alguma atividade remuneratória. Em 2010, a amostra é composta por 10.094.658 observações, sendo 6.351.146 ocupados em alguma atividade remuneratória.

As variáveis utilizadas como controles nas estimativas e também na elaboração das estatísticas descritivas estão resumidas no Quadro 1. Para a criação da dummy de migração, é necessário realizar adaptações em algumas variáveis. Como pode ser notado no Quadro 2, a dummy de migração foi criada com base na pergunta de data fixa do Censo. A pergunta é referente à moradia de exatamente cinco anos antes da pesquisa (1995 e 2005). Logo, migrante é aquele indivíduo que mudou de cidade nos últimos cinco anos.

\section{Resultados das descritivas e das estimações}

Nesta seção são apresentadas descrições com relação aos atributos pessoais e atributos dos postos de trabalho para os anos de 2000 e 2010. As estatísticas são ponderadas por um peso de expansão populacional.

A Tabela 1 mostra que a maior parte da população brasileira é composta por não migrantes. Entre os ocupados, percebe-se que o percentual de migrantes e de migrantes de retorno é maior do que do restante da população nos dois anos. Houve crescimento da preponderância de não migrantes no período, ou seja, houve uma queda do fluxo migratório no Brasil. Entre os ocupados, a redução é de, aproximadamente, dois pontos percentuais. Com relação à migração de retorno, os dados mostram que houve uma expansão desse fenômeno no período. Em termos absolutos, esse aumento foi considerável. Para a população total, se, em 2000, o Brasil tinha aproximadamente 967.000 migrantes de retorno, em 2010, alcançou 1.371 .000 pessoas.

Pela análise da Tabela 2, nota-se que os perfis do migrante e do migrante de retorno sofreram poucas alterações nos últimos dez anos. Em 2000, para os dois tipos de migrantes, o percentual de homens era mais elevado do que o de mulheres e se manteve em 2010. Já entre os não migrantes, o percentual de mulheres era mais elevado em 2000 e se manteve em 2010. Com relação à cor, em 2000, para os três grupos analisados, o percentual de brancos supera o daqueles que declaram ser preto e pardo. Em 2010, entretanto, tal proporção ultrapassou o percentual de brancos, tanto entre os não migrantes quanto entre os migrantes de retorno.

A literatura sobre migração aponta que os migrantes são geralmente jovens a procura de melhores oportunidades (Sjaastad, 1962; Borjas, 2004). No Brasil, não é diferente: os migrantes e migrantes de retorno são, em média, mais jovens que os não migrantes. Com relação à educação formal, os migrantes possuem, em média, maior nível de escolaridade que os não migrantes e os anos de estudo ampliaram-se para todos na década. 
Quadro 1 - Descrição das variáveis

\begin{tabular}{|c|c|}
\hline Área de residência & Igual a 1 se vive em área urbana e igual a 0 se em área rural. \\
\hline Cor ou raça & $\begin{array}{l}\text { Categórica que define se a pessoa é de cor branca, preta ou } \\
\text { parda. }\end{array}$ \\
\hline Estado civil & $\begin{array}{l}\text { Categórica que define se o indvíduo é casado(a), desquitado(a) ou } \\
\text { separado(a) judicialmente, divorciado(a), viúvo(a), ou solteiro(a). }\end{array}$ \\
\hline Idade & $\begin{array}{l}\text { Em anos completos na datas de refêrencia 01/08/2000 e } \\
31 / 07 / 2010 \text {. }\end{array}$ \\
\hline Idade 2 & Idade elevada ao quadrado. \\
\hline Informal & $\begin{array}{l}\text { Dummy igual a } 1 \text { se trabalha no setor informal (trabalhadores sem } \\
\text { carteira assinada e conta-próprias que não contribuem para a } \\
\text { previdência) e igual a } 0 \text { do contrário (trabalhadores com carteira } \\
\text { assinada, funcionários públicos, militares, empregadores e conta } \\
\text { próprias que contribuem para a previdência. }\end{array}$ \\
\hline Jornada & $\begin{array}{l}\text { Jornada de trabalho semanal média no trabalho principal nos } \\
\text { meses de julho de } 2000 \text { e } 2010 \text {. }\end{array}$ \\
\hline Nível de instrução & $\begin{array}{l}\text { Categórica que define se o indivíduo não possui instrução ou tem } \\
\text { o fundamental incompleto, se possui o fundamental completo ou } \\
\text { médio incompleto, se possui o médio completo ou superior incom- } \\
\text { pleto, ou se possui o superior completo. }\end{array}$ \\
\hline Pesdom & Número de pessoas no domicílio. \\
\hline Região & Região geográfica de residência. \\
\hline Rendimento & $\begin{array}{l}\text { Rendimento no trabalho principal nos meses de julho de } 2000 \text { e } \\
2010 .\end{array}$ \\
\hline Rendimento domiciliar & Rendimento domiciliar nos meses de julho de 2000 e 2010. \\
\hline Rendimento domiciliar & $\begin{array}{l}\text { Rendimento domiciliar per capita nos meses de julho de } 2000 \text { e } \\
2010 \text {. }\end{array}$ \\
\hline Rendimento hora & $\begin{array}{l}\text { Rendimento médio hora no trabalho principal nos meses de julho } \\
\text { de } 2000 \text { e } 2010 .\end{array}$ \\
\hline Rendimento total & $\begin{array}{l}\text { Rendimento em todos os trabalhos nos meses de julho de } 2000 \text { e } \\
2010 \text {. }\end{array}$ \\
\hline Sabe ler e escrever? & Dummy igual a 1 se sim e igual a 0 se não. \\
\hline Sexo & Dummy igual a 1 se masculino e igual a 0 se feminino. \\
\hline Trabalho & Dummy que define se o indivíduo possui trabalho remunerado. \\
\hline Trabalhos & $\begin{array}{l}\text { Dummy igual a } 1 \text { se possui um trabalho e igual a } 2 \text { se possui dois } \\
\text { ou mais. }\end{array}$ \\
\hline Tempo & Tempo médio de moradia no mesmo município sem interrupção. \\
\hline UF & Unidade da Federação de residência. \\
\hline
\end{tabular}

Fonte: Elaboração própria. 
Quadro 2 - Criação da dummy de migração

\begin{tabular}{|c|c|}
\hline Variáveis do Censo 2000 & \\
\hline Perguntas & Respostas possiveis \\
\hline $\begin{array}{l}1 \text { - Tempo de moradia no município } \\
2 \text { - Município de residência em } 1^{\circ} \text { de agosto } \\
\text { de } 1995 \\
3 \text { - Município de residência em } 1^{\circ} \text { de agosto } \\
\text { de } 2000\end{array}$ & $\begin{array}{l}0 \text { a } 65 \text { anos. Branco para quem nunca migrou } \\
\text { de município. }\end{array}$ \\
\hline \multicolumn{2}{|l|}{$\begin{array}{l}\text { Variável Criada a partir } \\
\text { das perguntas anteriores: }\end{array}$} \\
\hline Migrante & Respostas dadas às perguntas anteriores \\
\hline $\begin{array}{l}1 \text { - Migrante de única etapa ou progressivo } \\
2 \text { - Migrante de retorno } \\
0 \text { - Natural ou nativo }\end{array}$ & $\begin{array}{l}\text { Respostas distintas às perguntas } 2 \text { e } 3 . \\
\text { Sua resposta é idêntica nas perguntas } 2 \text { e } 3 \\
\text { e mora há menos de cinco anos no mesmo } \\
\text { município. } \\
\text { Tempo de moradia no municípo igual a cinco } \\
\text { anos ou mais, ou valor em branco. }\end{array}$ \\
\hline \multicolumn{2}{|l|}{ Variáveis do Censo 2010} \\
\hline Perguntas & Respostas possíveis \\
\hline $\begin{array}{l}1 \text { - Tempo de moradia no município } \\
2 \text { - Município de residência em } 31 \text { de julho } \\
2005 \\
3 \text { - Município de residência em } 31 \text { de julho de } \\
2010 \\
\text { 4- Município de residência anterior }\end{array}$ & $\begin{array}{l}0 \text { a } 65 \text { anos. Branco para quem nunca migrou } \\
\text { de município. }\end{array}$ \\
\hline \multicolumn{2}{|l|}{$\begin{array}{c}\text { Variável criada a partir das perguntas } \\
\text { anteriores: }\end{array}$} \\
\hline Migrante & Respostas dadas às perguntas anteriores \\
\hline $\begin{array}{l}\text { 1- Migrante de única etapa ou progressivo } \\
\text { 2- Migrante de retorno }\end{array}$ & $\begin{array}{l}\text { Respostas distintas às perguntas } 2 \text { e } 3 . \\
\text { Sua resposta é idêntica nas perguntas } 2 \text { e } 3 \\
\text { e mora há menos de cinco anos no mesmo } \\
\text { município. }\end{array}$ \\
\hline 0 - Natural ou nativo & $\begin{array}{l}\text { Tempo de moradia no municípo igual a cinco } \\
\text { anos ou mais, ou valor em branco. }\end{array}$ \\
\hline
\end{tabular}

Fonte: Elaboração própria a partir dos dados dos Censos 2000 e 2010.

Tabela 1 - Proporção de migrantes, migrantes de retorno e não migrantes

\begin{tabular}{l|c|c|c|c}
\hline \multirow{2}{*}{} & \multicolumn{2}{|c|}{ População total } & \multicolumn{2}{c}{ Ocupados } \\
\cline { 2 - 5 } & 2000 & 2010 & 2000 & 2010 \\
\hline Não Migrantes & 88,91 & 90,94 & 88,82 & 90,71 \\
\hline Migrantes & 9,78 & 7,61 & 9,86 & 7,80 \\
\hline Migrantes de retorno & 1,31 & 1.45 & 1,32 & 1,48 \\
\hline
\end{tabular}

Fonte: Elaboração própria. 
Tabela 2 - Atributos pessoais de migrantes e não migrantes

\begin{tabular}{|c|c|c|c|c|c|c|c|c|}
\hline \multirow[t]{2}{*}{ Variáveis } & \multicolumn{2}{|c|}{ Não Migrante } & \multicolumn{2}{|c|}{ Migrante } & \multicolumn{2}{|c|}{$\begin{array}{l}\text { Migrante } \\
\text { de retorno }\end{array}$} & \multicolumn{2}{|c|}{ Total } \\
\hline & 2000 & 2010 & 2000 & 2010 & 2000 & 2010 & 2000 & 2010 \\
\hline Sexo (\% masculino) & 48,19 & 48,17 & 51,07 & 51,43 & 52,84 & 50,53 & 48,53 & 48,46 \\
\hline \multicolumn{9}{|l|}{ Cor (\%) } \\
\hline Branca e Amarela & 56,96 & 50,19 & 57,59 & 52,50 & 54,94 & 50,59 & 57,00 & 50,37 \\
\hline Preta & 6,93 & 8,39 & 5,84 & 7,63 & 6,45 & 7,76 & 6,82 & 8,32 \\
\hline Parda & 36,11 & 41,42 & 36,56 & 39,87 & 38,61 & 41,65 & 36,18 & 41,30 \\
\hline $\begin{array}{l}\text { Vive em região urbana } \\
\text { ou rural? (\% Urbana) }\end{array}$ & 83,32 & 85,92 & 83,94 & 86,58 & 83,62 & 88,31 & 83,38 & 86,00 \\
\hline Idade & 41,10 & 41,86 & 37,85 & 37,98 & 37,63 & 37,70 & 40,74 & 41,51 \\
\hline $\begin{array}{l}\text { Tempo de Moradia no } \\
\text { Município }\end{array}$ & 29,72 & 31,80 & 2,06 & 1,90 & 1,96 & 1,84 & 26,65 & 29,09 \\
\hline $\begin{array}{l}\text { Sabe ler e escrever? } \\
\text { (\% sim) }\end{array}$ & 86,38 & 90,55 & 88,43 & 92,98 & 86,34 & 92,39 & 86,58 & 90,76 \\
\hline \multicolumn{9}{|l|}{ Nível de Instrução (\%) } \\
\hline $\begin{array}{l}\text { Sem Instrução e } \\
\text { Fundmental Incompleto }\end{array}$ & 61,11 & 45,98 & 57,61 & 39,51 & 61,12 & 41,75 & 60,76 & 45,42 \\
\hline $\begin{array}{l}\text { Fundamental Completo } \\
\text { e Médio incompleto }\end{array}$ & 13,64 & 15,62 & 14,44 & 15,57 & 14,15 & 16,33 & 13,72 & 15,63 \\
\hline $\begin{array}{l}\text { Médio completo e } \\
\text { superior incompleto }\end{array}$ & 22,41 & 26,69 & 24,17 & 28,57 & 21,43 & 27,17 & 22,57 & 26,84 \\
\hline Superior Completo & 2,84 & 11,72 & 3,79 & 16,35 & 3,30 & 14,75 & 2,94 & 12,11 \\
\hline \multicolumn{9}{|l|}{ Estado Civil (\%) } \\
\hline Casado(a) & 57,05 & 49,14 & 53,88 & 44,27 & 51,13 & 43,19 & 56,66 & 48,68 \\
\hline $\begin{array}{l}\text { Desquitado(a) } \\
\text { ou separado(a) } \\
\text { judicialmente }\end{array}$ & 3,05 & 2,48 & 3,85 & 2,90 & 4,02 & 2,91 & 3,14 & 2,52 \\
\hline Divorciado(a) & 2,75 & 4,55 & 3,43 & 5,53 & 3,40 & 5,34 & 2,82 & 4,63 \\
\hline Viúvo(a) & 4,12 & 3,71 & 3,04 & 2,69 & 3,28 & 2,71 & 4,01 & 3,62 \\
\hline Solteiro(a) & 33,02 & 40,12 & 35,81 & 44,60 & 38,17 & 45,85 & 33,36 & 40,54 \\
\hline $\begin{array}{l}\text { Número médio de } \\
\text { pessoas por domicílio }\end{array}$ & 4,32 & 3,85 & 4,04 & 3,51 & 4,09 & 3,66 & 4,29 & 3,82 \\
\hline Renda Domiciliar & 2185,76 & 2881,60 & 2171,34 & 3256,00 & 1911,83 & 3144,77 & 2180,77 & 2913,46 \\
\hline $\begin{array}{l}\text { Renda Domiciliar per } \\
\text { capita }\end{array}$ & 611,61 & 890,84 & 678,26 & 1156,79 & 594,34 & 1078,28 & 617,90 & 913,48 \\
\hline $\begin{array}{l}\text { Possui Trabalho } \\
\text { Remunerado? (\% sim) }\end{array}$ & 59,04 & 64,96 & 59,62 & 66,81 & 59,79 & 66,46 & 59,11 & 65,12 \\
\hline
\end{tabular}

Fonte: Elaboração própria a partir do dados dos Censos 2000 e 2010. 
Ademais, observa-se que realmente houve aumento do percentual de ocupados. Em 2000, a maior parcela de indivíduos trabalhando estava entre os migrantes de retorno. Em 2010, os migrantes de não retorno passaram a apresentar o maior percentual de pessoas empregadas, seguidas pelos migrantes de retorno.

Com relação à variável estado civil, o mais importante a atentar é a expressiva redução no percentual de pessoas casadas em contraposição ao aumento de solteiras, o que coincide com a queda do número médio de pessoas por domić́lio. Dados a diminuição do número de moradores por domicílio e o aumento da renda domiciliar, não é de estranhar um aumento ainda maior da renda domiciliar per capita, em torno de $48 \%$.

A Tabela 3 mostra como é preponderante a participação masculina no mercado de trabalho brasileiro, principalmente entre os migrantes. Porém, a mulher ganhou espaço nos últimos anos. Com relação à cor, percebe-se que os que se declaram brancos apresentam proporção consideravelmente mais elevada entre os ocupados em comparação à população total. Entretanto, a participação dos declarados pretos e pardos no mercado de trabalho brasileiro cresceu no período analisado, principalmente entre os pretos migrantes e os pardos não migrantes. Pela leitura da Tabela 1 , nota-se que o fluxo migratório é mais intenso entre os ocupados em comparação ao restante da população. Consequentemente, o tempo médio de moradia sem interrupção no mesmo município é menor entre os ocupados. Atentando-se apenas aos resultados da Tabela 3, observa-se que, em 2010, o tempo médio de moradia para os dois tipos de migrantes diminuiu.

$\mathrm{Na}$ esteira das políticas de incentivo à formalização, verifica-se um aumento da participação dos trabalhadores formais nos três grupos analisados entre 2000 e 2010. O maior percentual de trabalhadores informais encontra-se no grupo denominado migrantes de retorno. A jornada média de trabalho caiu aproximadamente $8 \%$ no período, mas, mesmo assim, o rendimento no trabalho principal apresentou um crescimento de quase 16\%. Percebe-se que, em 2010, são os migrantes de não retorno que permanecem mais tempo no trabalho principal e recebem os maiores rendimentos. Resumindo, a situação dos trabalhadores brasileiros melhorou consideravelmente no período intercensitário, dado que estão ganhando mais e trabalhando menos.

Quando se analisa o rendimento em todos os trabalhos, nota-se que seu crescimento foi um pouco maior do que no trabalho principal, da ordem de 17\%. Provavelmente, isso se deve ao fato de que o percentual de trabalhadores com dois ou mais vínculos aumentou no período. É entre os migrantes de retorno e também de não retorno que a parcela de trabalhadores com dois ou mais trabalhos é maior. 
Tabela 3 - Atributos pessoais e do posto de trabalho para a população ocupada

\begin{tabular}{|c|c|c|c|c|c|c|c|c|}
\hline \multirow[t]{2}{*}{ Variáveis } & \multicolumn{2}{|c|}{ Não Migrante } & \multicolumn{2}{|c|}{ Migrante } & \multicolumn{2}{|c|}{$\begin{array}{l}\text { Migrante } \\
\text { de retorno }\end{array}$} & \multicolumn{2}{|c|}{ Total } \\
\hline & 2000 & 2010 & 2000 & 2010 & 2000 & 2010 & 2000 & 2010 \\
\hline Sexo (\% masculino) & 62,34 & 57,40 & 67,37 & 62,29 & 67,83 & 61,44 & 62,91 & 57,85 \\
\hline \multicolumn{9}{|l|}{ Cor (\%) } \\
\hline Branca e Amarela & 58,70 & 52,68 & 58,96 & 54,37 & 56,54 & 52,57 & 58,69 & 52,81 \\
\hline Preta & 6,89 & 8,41 & 5,85 & 7,72 & 6,36 & 7,74 & 6,78 & 8,34 \\
\hline Parda & 34,42 & 38,92 & 35,19 & 37,91 & 37,10 & 39,69 & 34,53 & 38,85 \\
\hline $\begin{array}{l}\text { Vive em região urbana } \\
\text { ou rural? (\% Urbana) }\end{array}$ & 86,23 & 89,45 & 85,70 & 89,12 & 85,28 & 90,64 & 86,16 & 89,44 \\
\hline Idade & 39,43 & 40,40 & 36,56 & 36,67 & 36,53 & 36,63 & 39,10 & 40,05 \\
\hline $\begin{array}{l}\text { Tempo de Moradia no } \\
\text { Município }\end{array}$ & 28,41 & 30,49 & 2,11 & 1,95 & 2,00 & 1,89 & 25,47 & 27,84 \\
\hline $\begin{array}{l}\text { Sabe ler e escrever? } \\
(\% \operatorname{sim})\end{array}$ & 90,96 & 94,48 & 91,53 & 95,30 & 89,71 & 94,82 & 91,00 & 94,55 \\
\hline \multicolumn{9}{|l|}{ Nível de Instrução (\%) } \\
\hline $\begin{array}{l}\text { Sem Instrução e } \\
\text { Fundmental Incompleto }\end{array}$ & 53,15 & 38,12 & 51,84 & 33,91 & 55,48 & 36,38 & 53,05 & 37,77 \\
\hline $\begin{array}{l}\text { Fundamental Completo } \\
\text { e Médio incompleto }\end{array}$ & 14,75 & 16,13 & 14,85 & 15,35 & 14,79 & 16,22 & 14,76 & 16,08 \\
\hline $\begin{array}{l}\text { Médio completo e } \\
\text { superior incompleto }\end{array}$ & 27,97 & 30,50 & 27,97 & 30,55 & 25,10 & 29,22 & 27,93 & 30,49 \\
\hline Superior Completo & 4,13 & 15,24 & 5,34 & 20,18 & 4,64 & 18,18 & 4,25 & 15,67 \\
\hline $\begin{array}{l}\text { Trabalha no Setor } \\
\text { Informal? (\% sim) }\end{array}$ & 42,20 & 35,76 & 45,06 & 34,86 & 48,20 & 36,97 & 42,56 & 35,70 \\
\hline $\begin{array}{l}\text { Jornada de Trabalho } \\
\text { Semanal Média no } \\
\text { trabalho Principal }\end{array}$ & 44,23 & 40,88 & 45,97 & 42,30 & 45,27 & 41,07 & 44,41 & 40,99 \\
\hline $\begin{array}{l}\text { Rendimento médio no } \\
\text { trabalho Principal }\end{array}$ & 1229,78 & 1399,44 & 1356,94 & 1732,09 & 1197,90 & 1625,11 & 1241,90 & 1428,75 \\
\hline $\begin{array}{l}\text { Rendimento médio em } \\
\text { todos os trabalhos }\end{array}$ & 1275,24 & 1461,16 & 1400,57 & 1806,30 & 1236,31 & 1697,69 & 1287,09 & 1491,61 \\
\hline $\begin{array}{l}\text { Rendimento Médio Hora } \\
\text { no Trabalho Principa }\end{array}$ & 7,65 & 10,71 & 8,24 & 12,46 & 7,58 & 12,70 & 7,71 & 10,88 \\
\hline \multicolumn{9}{|l|}{$\begin{array}{l}\text { Quantos trabalhos } \\
\text { tinha (\% sim) }\end{array}$} \\
\hline Um & 95,61 & 94,87 & 95,88 & 94,69 & 95,92 & 94,69 & 95,64 & 94,85 \\
\hline Dois ou mais & 4,39 & 5,13 & 4,12 & 5,31 & 4,08 & 5,31 & 4,36 & 5,15 \\
\hline
\end{tabular}

Fonte: Elaboração própria a partir do dados dos Censos 2000 e 2010.

Como em um modelo de seleção uma ou mais variáveis devem ser escolhidas para servirem de instrumento, em outras palavras, devem ser inseridas na equação de escolha ( $1^{\circ}$ estágio), mas não na equação de rendimentos $\left(2^{\circ}\right.$ estágio), o ideal é que sejam escolhidas aquelas que afetam a variável de decisão no 
primeiro estágio, mas que não influenciem a variável dependente no segundo. As variáveis de estado civil e de renda familiar per capita, através de análise correlação, apresentaram esse padrão. Dessa forma, elas são utilizadas como instrumentos.

Na Tabela 4, apresentam-se os resultados da estimação do modelo probit multinomial. As amostras são compostas tanto por aqueles indivíduos que possuíam algum rendimento na semana de referência da pesquisa quanto pelos desocupados ou trabalhadores sem remuneração.

Como esperado, em ambos os anos, ser mulher diminui a probabilidade de realização dos dois tipos migrações, porém o efeito era mais elevado em 2000 do que em 2010. Além disso, o efeito do gênero é bem mais elevado sobre a migração de não retorno do que sobre a migração de retorno, nos dois anos. Também, os pretos e pardos possuem menor probabilidade de migrar que os brancos, todavia os brancos eram menos propensos a migrar do que os pardos em 2000. Em 2010, declarar-se pardo não se mostrou significativo para explicar a migração.

Com relação à idade, os resultados são idênticos para 2000 e 2010. Percebe-se que o efeito da idade sobre a migração de não retorno é mais forte do que sobre a migração de retorno. Alguns estudiosos (Borjas, 2004; Dustmann; Glitz, 2011) afirmam que, quanto mais escolarizado um indivíduo, maior a probabilidade que ele migre e se estabeleça. Analisando a Tabela 4, percebe-se que, em 2000 e 2010, concluir Ensino Superior aumentava em 2,2 pontos percentuais a probabilidade de um indivíduo migrar no ano de 2000, e em 2,3 no ano de 2010. Ter cursado o Fundamental completo ou Ensino Médio incompleto diminuía a probabilidade de migrar em comparação ao grupo de referência, em 2000, e não exercia influência em 2010. Com relação à migração de retorno, os resultados são similares em 2000 e 2010.

De acordo com os resultados apresentados na Tabela 4, em ambos os anos, residir em regiões metropolitanas ou rurais diminui a probabilidade de o indivíduo ser migrante. Era esperado que as regiões metropolitanas, por oferecerem maiores oportunidades de emprego, fossem mais atrativas aos migrantes. Com relação à área rural, o resultado é o esperado. No que tange à migração de retorno, houve uma mudança de padrão no período. Se, em 2000, a probabilidade de retorno era maior fora de regiões metropolitanas, em 2010, esse padrão se inverteu.

Concernente à região geográfica de residência, moradores de todas as regiões apresentavam maior probabilidade de serem migrantes do que aqueles residentes no Nordeste em 2000 e em 2010. Quando o foco de análise passa para a migração de retorno, os resultados se alteram. Em 2000, os resultados mostram que o Nordeste é mais atrativo para os migrantes de retorno do que o Sul ou do Sudeste, enquanto o Centro-Oeste é mais atrativo aos migrantes de retorno. Em 2010, a propensão a remigrar era maior em todas as regiões em comparação ao Nordeste.

Era esperado, como abordado na seção teórica, que indivíduos solteiros apresentassem maior probabilidade de migrar do que casados, porém o resul- 
tado foi o oposto, ou seja, indivíduos casados apresentavam, em 2000 e 2010, maior probabilidade de migrar do que os solteiros.

O coeficiente da variável renda familiar per capita apresenta sinal positivo e é significativo nas duas estimativas. Porém, os valores dos coeficientes são muito baixos, indicando que a renda familiar per capita exerce influência desprezível sobre as decisões por migrar, quando se controla por vários outros atributos. Finalizando a análise da Tabela 4, nota-se que mulheres, indivíduos que se declaram pretos e pessoas mais velhas apresentam menor probabilidade de realizar ambas as migrações. Além disso, o efeito da cor e do gênero sobre a decisão por migrar caiu no período analisado. Na maior parte dos casos, o efeito das variáveis é maior para a migração do que para a migração de retorno.

Após estimadas as equações de escolha por migrar, cujos coeficientes se encontram na Tabela 4 , foram geradas as razões inversas de Mills $\left(\ddot{e}_{k}\right)$. Essas razões foram incluídas como regressores adicionais nas estimativas mostradas nas Tabelas 5 e 6 . Se o coeficiente é significativo fica evidenciada a presença do viés de seleção e ele é automaticamente corrigido.

Todas as equações de rendimentos apresentadas nas Tabelas 5 e 6 foram estimadas por MQO, ponderados por pesos amostrais. ${ }^{3}$ Os resultados para os anos 2000 e 2010 evidenciam a seleção positiva dos migrantes com relação às habilidades não observadas, dado que a razão inversa de Mills se mostrou significativa a $1 \%$ em todas as estimativas onde incluída. Ademais, os sinais dos coeficientes foram todos positivos (Tabela 5 ). Isso indica que fatores não mensurados aumentam a probabilidade de migrar e também elevam os rendimentos. Com a migração de retorno, o efeito é ambíguo em 2000, pois, na primeira especificação, em que são considerados somente migrantes de retorno e não migrantes, sexo e cor elevam a probabilidade de um trabalhador migrar, porém decrescem seus rendimentos. Já na estimativa (6), onde são incluídos mais controles, o sinal do coeficiente de $\lambda_{2}$ é positivo. Em 2010, os migrantes de retorno se mostram positivamente selecionados em todas as especificações. Vale ressaltar que não há necessariamente uma relação entre os dois tipos de seleções (Borjas, 1988).

Tabela 4 - Probit multinomial para os dados de 2000 e 2010 (efeitos marginais reportados)

\begin{tabular}{|c|c|c|c|c|}
\hline \multirow[t]{2}{*}{ Variáveis } & \multicolumn{2}{|c|}{2000} & \multicolumn{2}{|c|}{2010} \\
\hline & Migrante & Migrante Ret. & Migrante & Migrante Ret. \\
\hline Sexo (masculino omitido) & $\begin{array}{c}-0,010^{\star \star \star} \\
(0,000)\end{array}$ & $\begin{array}{c}-0,002^{\star * *} \\
(0,000)\end{array}$ & $\begin{array}{c}-, 008^{\star * *} \\
(0,000)\end{array}$ & $\begin{array}{c}-0,001^{* \star *} \\
(0,000)\end{array}$ \\
\hline \multicolumn{5}{|l|}{ Cor (branca omitida) } \\
\hline Preta & $\begin{array}{c}-0,009^{\star * *} \\
(0,000)\end{array}$ & $\begin{array}{c}-0,001^{* * *} \\
(0,000)\end{array}$ & $\begin{array}{c}-0,002^{* * *} \\
(0,000)\end{array}$ & $\begin{array}{c}-0,001^{\star * *} \\
(0,000)\end{array}$ \\
\hline
\end{tabular}




\begin{tabular}{|c|c|c|c|c|}
\hline Parda & $\begin{array}{c}0,002^{* \star \star} \\
(0,000)\end{array}$ & $\begin{array}{c}0,000^{\star \star *} \\
(0,000)\end{array}$ & $\begin{array}{l}-0,000 \\
(0,000)\end{array}$ & $\begin{array}{l}0,000 \\
(0,000)\end{array}$ \\
\hline Idade & $\begin{array}{c}-0,005^{\star \star *} \\
(0,000)\end{array}$ & $\begin{array}{c}-0,001^{* * *} \\
(0,000)\end{array}$ & $\begin{array}{c}-0,005^{\star * *} \\
(0,000)\end{array}$ & $\begin{array}{l}-0,001 \\
(0,000)\end{array}$ \\
\hline Idade ao quadrado & $\begin{array}{l}0,000^{* * *} \\
(0,000)\end{array}$ & $\begin{array}{l}0,000^{* * *} \\
(0,000)\end{array}$ & $\begin{array}{c}0,000^{* * *} \\
(0,000)\end{array}$ & $\begin{array}{l}0,000^{* * *} \\
(0,000)\end{array}$ \\
\hline \multicolumn{5}{|l|}{$\begin{array}{l}\text { Nível de instrução ( sem } \\
\text { instrução e fundamenteal } \\
\text { incompleto omitido) }\end{array}$} \\
\hline $\begin{array}{l}\text { Fundamental completo e médio } \\
\text { incompleto }\end{array}$ & $\begin{array}{c}-0,002^{\star \star \star} \\
(0,000)\end{array}$ & $\begin{array}{c}-0,001^{* * *} \\
(0,000)\end{array}$ & $\begin{array}{l}-0,000 \\
(0,000)\end{array}$ & $\begin{array}{l}-0,001^{* * \star} \\
(0,000)\end{array}$ \\
\hline $\begin{array}{l}\text { Médio completo e superior } \\
\text { incompleto }\end{array}$ & $\begin{array}{c}0,000 \\
(0,000)\end{array}$ & $\begin{array}{c}-0,002^{\star \star \star} \\
(0,000)\end{array}$ & $\begin{array}{l}0,001^{\star \star \star} \\
(0,000)\end{array}$ & $\begin{array}{c}-0,002^{\star \star \star} \\
(0,000)\end{array}$ \\
\hline Superior Completo & $\begin{array}{l}0,022^{* \star *} \\
(0,001)\end{array}$ & $\begin{array}{c}0,001^{\star \star \star} \\
(0,000)\end{array}$ & $\begin{array}{l}0,023^{\star \star \star} \\
(0,000)\end{array}$ & $\begin{array}{l}0,001^{\star \star *} \\
(0,000)\end{array}$ \\
\hline $\begin{array}{l}\text { Vive rem região metropolitana? } \\
\text { (não omitido) }\end{array}$ & $\begin{array}{c}-0,005^{\star \star \star} \\
(0,000)\end{array}$ & $\begin{array}{l}-0,001 \\
(0,000)\end{array}$ & $\begin{array}{l}-0,011^{\star \star \star} \\
(0,000)\end{array}$ & $\begin{array}{l}0,001^{* \star *} \\
(0,000)\end{array}$ \\
\hline \multicolumn{5}{|l|}{$\begin{array}{l}\text { Região de residência (Nordeste } \\
\text { omitida) }\end{array}$} \\
\hline Norte & $\begin{array}{c}0,041^{\star \star \star} \\
(0,001)\end{array}$ & $\begin{array}{c}0,000 \\
(0,000)\end{array}$ & $\begin{array}{l}0,024^{\star * *} \\
(0,000)\end{array}$ & $\begin{array}{c}0,003^{* * *} \\
(0,000)\end{array}$ \\
\hline Sudeste & $\begin{array}{l}0,009^{\star * *} \\
(0,000)\end{array}$ & $\begin{array}{c}-0,001^{* * *} \\
(0,000)\end{array}$ & $\begin{array}{l}0,008^{\star \star \star} \\
(0,000)\end{array}$ & $\begin{array}{l}0,001^{\star \star *} \\
(0,000)\end{array}$ \\
\hline Sul & $\begin{array}{l}0,028^{\star * *} \\
(0,000)\end{array}$ & $\begin{array}{c}-0,002^{\star \star \star} \\
(0,000)\end{array}$ & $\begin{array}{c}0,032^{\star \star \star} \\
(0,000)\end{array}$ & $\begin{array}{c}0,002^{\star \star *} \\
(0,000)\end{array}$ \\
\hline Centro-Oeste & $\begin{array}{c}0,069^{* * \star} \\
(0,001)\end{array}$ & $\begin{array}{l}0,001^{* * *} \\
(0,000)\end{array}$ & $\begin{array}{c}0,052^{* * *} \\
(0,000)\end{array}$ & $\begin{array}{l}0,010^{* * *} \\
(0,000)\end{array}$ \\
\hline $\begin{array}{l}\text { Vive em região urbana ou rural? } \\
\text { (urbana omitido) }\end{array}$ & $\begin{array}{l}0,001^{* * *} \\
(0,000)\end{array}$ & $\begin{array}{c}-0,001^{* \star \star} \\
(0,000)\end{array}$ & $\begin{array}{c}-0,003^{\star * \star} \\
(0,000)\end{array}$ & $\begin{array}{c}-0,002^{\star * *} \\
(0,000)\end{array}$ \\
\hline \multicolumn{5}{|l|}{ Estado Civil (casado omitido) } \\
\hline $\begin{array}{l}\text { Desquitado(a) ou separado(a) } \\
\text { judicialmente }\end{array}$ & $\begin{array}{l}0,033^{* * *} \\
(0,001)\end{array}$ & $\begin{array}{l}0,007^{* * *} \\
(0,000)\end{array}$ & $\begin{array}{c}0,025^{\star * *} \\
(0,001)\end{array}$ & $\begin{array}{l}0,005^{* * *} \\
(0,000)\end{array}$ \\
\hline Divorciado(a) & $\begin{array}{c}0,032^{* \star *} \\
(0,001)\end{array}$ & $\begin{array}{l}0,006^{\star \star *} \\
(0,000)\end{array}$ & $\begin{array}{c}0,029^{\star \star \star} \\
(0,001)\end{array}$ & $\begin{array}{c}0,006^{\star * \star} \\
(0,000)\end{array}$ \\
\hline Viúvo(a) & $\begin{array}{c}0,010^{\star * \star} \\
(0,001)\end{array}$ & $\begin{array}{l}0,003^{\star \star *} \\
(0,000)\end{array}$ & $\begin{array}{c}0,013^{\star \star *} \\
(0,001)\end{array}$ & $\begin{array}{l}0,003^{\star \star *} \\
(0,000)\end{array}$ \\
\hline Viúvo(a) & $\begin{array}{c}-0,003^{\star * \star} \\
(0,000)\end{array}$ & $\begin{array}{l}0,000^{\star \star \star} \\
(0,000)\end{array}$ & $\begin{array}{c}-0,002^{\star * \star} \\
(0,000)\end{array}$ & $\begin{array}{l}-0,000 \\
(0,000)\end{array}$ \\
\hline Rendimento Domiciliar per capita & $\begin{array}{c}0,000^{\star \star \star} \\
(0,000)\end{array}$ & $\begin{array}{l}0,000^{\star \star \star} \\
(0,000)\end{array}$ & $\begin{array}{c}0,000^{\star \star \star} \\
(0,000)\end{array}$ & $\begin{array}{l}0,000^{\star * *} \\
(0,000)\end{array}$ \\
\hline Prob $>$ Wald & 0,000 & 0,000 & 0,000 & 0,000 \\
\hline Observações & 8.716 .045 & 8.716 .045 & 10.094 .658 & 10.094 .658 \\
\hline
\end{tabular}

Fonte: Elaboração própria a partir dos resultados das estimativas.

Nota: *** Significativo a 1\%. Erro-padrão entre parênteses. 
Ser migrante em comparação aos não migrantes em 2010 eleva os rendimentos em um percentual bem mais alto do que o verificado em 2000. Comparando-se as equações estimadas (2) e (4), nota-se que o retorno ao migrante aproximadamente seis pontos percentuais no período. Os resultados para a migração de retorno, quando as estimativas contam com mais controles (6 e 8), apontam que os migrantes de retorno seriam positivamente selecionados com relação às características não mensuráveis nos dois anos, porém ser migrante de retorno não influencia os rendimentos de um trabalhador em 2000. Entretanto, em 2010, ser migrante de retorno aumenta o rendimento em 7,8\% $\left(\exp ^{(0,075)}-1\right)$. Analisando os resultados das quatro estimativas para o ano de 2000, nota-se que, a cada ano adicional de vida, o rendimento aumenta entre $7,7 \%$ e $13,4 \%$, porém à medida que a idade se torna muito avançada, os retornos passam a decair. Em 2010 , cada ano a mais de idade eleva o rendimento no trabalho entre $7,3 \% \mathrm{e}$ $10,8 \%$, e assim, como em 2000, à medida que a idade se torna mais avançada, os rendimentos dos trabalhadores passam a diminuir, corroborando o perfil côncavo do rendimento no ciclo de vida, seminalmente atestado por Borjas (2004) e de consenso na literatura.

Os resultados expostos na Tabela 5 apontam para a ainda presença de discriminação tanto de gênero quanto de cor no mercado de trabalho brasileiro. Porém, aparentemente os dois fenômenos ocorrem de forma distinta. Como o nível de instrução, a região de residência e o setor ocupacional são responsáveis por boa parte dos diferenciais de rendimentos, pode-se inferir que a discriminação contra as mulheres é grande, independentemente do nível de escolaridade, da região em que ela vive ou onde trabalha. Já a discriminação racial parece estar muito interligada com questões regionais, com a escolaridade, até mesmo porque pretos e pardos são, em média, menos escolarizados que os brancos, e com a questão da inserção no mercado de trabalho. Isso é apenas um indício da presença de discriminação.

A região geográfica de residência influencia fortemente os rendimentos, conforme Barros et al. (2007). Com exceção na estimativa (2), residir no Norte, Sudeste, Sul e Centro-Oeste em comparação ao Nordeste aumenta o rendimento do trabalhador. Se considerarmos a estimativa que não inclui os migrantes de retorno, percebemos que houve aumento da divergência de renda no Norte, no Sul e no Centro-Oeste, e, no último, houve uma inversão em favor do Centro-Oeste. Se considerarmos as estimativas sem migrantes de não retorno, em todas as regiões, com exceção do Centro-Oeste, houve queda do diferencial de rendimentos em comparação ao Nordeste.

Observa-se que a divergência de renda é bem menor quando a análise é sobre as estimativas em que são considerados os migrantes. Logo, a migração deve contribuir para um menor diferencial de rendimentos entre as regiões. Porém, em 2000 e 2010, apenas entre o Nordeste e o Sudeste, o diferencial de retorno caiu. Dessa forma, uma questão emerge: por que, apesar de a migração 
contribuir para a convergência de renda, na amostra com migrantes houve aumento da divergência? A explicação encontra-se na diminuição do percentual de migrantes. Os migrantes contribuem para acrescer a renda no local de destino. Como o Nordeste é caracterizado por baixo percentual de migrantes e, além disso, apresentou diminuição considerável no período, isso contribuiu para que o diferencial de retornos crescesse no período.

A análise, considerando a migração de retorno, deve ser feita com maior cautela, em virtude do baixo percentual de migrantes de retorno em todas as regiões. Porém, quando se comparam as estimativas (2) e (4) e (6) e (8) (Tabela $5)$, nota-se que, em todas as regiões, o retorno é mais elevado na amostra que não considera os migrantes. Percebe-se, inclusive, que o Centro-Oeste é a região onde houve maior crescimento da migração de retorno e passou a apresentar, em 2010, o maior diferencial de rendimento em relação ao Nordeste, superando o Sudeste de 2000. Logo, ainda que a migração de retorno contribua para aumentos de rendimentos na localidade de destino, devido ao fato de o Nordeste ter apresentado queda do percentual de remigrantes em todos os seus estados, a migração de retorno sugere manter relação positiva com a divergência regional de renda no país.

Resumindo o restante dos resultados: conclui-se que o retorno à educação formal caiu significativamente entre 2000 e 2010 - provavelmente, em função do crescimento da escolaridade média da população. Maiores também são os retornos de quem vive em áreas urbanas e metropolitanas e trabalham no setor formal, com redução desses diferenciais entre 2000 e 2010. Além disso, o retorno de cada hora trabalhada a mais por mês é baixo, porém mostra-se significativo a $1 \%$ - talvez o baixo valor do retorno se deva ao fato de maior parte dos empregados no setor formal contarem com uma carga de trabalho predefinida em contrato de trabalho.

Na Tabela 6 estão registrados os resultados para migrantes de não retorno e migrantes de retorno, separadamente. Verifica-se a importância da idade para os rendimentos, principalmente entre os migrantes de não retorno. Um ano a mais de vida aumenta em mais de $12 \%$ o rendimento de migrantes de não retorno em 2000, e em mais de $9 \%$ em 2010. Entre os migrantes de retorno, o efeito da idade é menor, mas também elevado. Novamente, a relação entre renda e idade apresenta o formato de $\mathrm{U}$ invertido. Os sinais dos coeficientes dos lambdas mostram, mais uma vez, que migrantes e migrantes de retorno são positivamente selecionados.

Para os dois tipos, o padrão de discriminação mostrado na Tabela 5 se mantém, ou seja, com a inclusão de mais controles, o diferencial de rendimentos contras as mulheres aumenta e contra os que se declaram pretos e pardos decai, tanto em 2000 quanto em 2010. Além disso, estimativas com mais controles (2, 4,6 e 8 (Tabela 5)) mostram que a discriminação contra as mulheres migrantes e migrantes de retorno aumentou no período analisado. 
Tabela 5 - Resultados das estimações de rendimentos com inclusão da razão inversa de Mills para os anos 2000 e 2010

\begin{tabular}{|c|c|c|c|c|c|c|c|c|}
\hline \multicolumn{9}{|c|}{ Estimativas por MQO - Variável dependente: logaritmo do rendimento mensal } \\
\hline \multirow[b]{3}{*}{ VARIÁVEIS } & \multicolumn{4}{|c|}{ Migrantes } & \multicolumn{4}{|c|}{ Migrantes de Retorno } \\
\hline & \multicolumn{2}{|c|}{2000} & \multicolumn{2}{|c|}{2010} & \multicolumn{2}{|c|}{2000} & \multicolumn{2}{|c|}{2010} \\
\hline & (1) & (2) & (3) & (4) & (5) & (6) & (7) & (8) \\
\hline Idade & $\begin{array}{c}0,135^{\star \star \star} \\
-0,001\end{array}$ & \begin{tabular}{|c|}
$0,124^{\star * *}$ \\
$-0,002$
\end{tabular} & $\begin{array}{c}0,118^{\star \star *} \\
(0,003)\end{array}$ & $\begin{array}{c}0,091^{* \star *} \\
(0,003)\end{array}$ & $\begin{array}{c}0,091^{* * *} \\
-0,005\end{array}$ & $\begin{array}{c}0,096^{\star * *} \\
-0,004\end{array}$ & $\begin{array}{l}0,091^{*} \\
(0,010)\end{array}$ & $\begin{array}{c}0,063^{\star * *} \\
(0,005)\end{array}$ \\
\hline Idde ao quadrado & 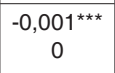 & $\begin{array}{c}-0,001^{* * *} \\
0\end{array}$ & $\begin{array}{c}-0,001^{\star * *} \\
(0,000)\end{array}$ & $\begin{array}{c}-0,001^{* * *} \\
(0,000)\end{array}$ & $\begin{array}{c}-0,001^{* * *} \\
0\end{array}$ & $\begin{array}{c}-0,001 \\
0\end{array}$ & $\begin{array}{c}-0,001^{* \star *} \\
(0,000)\end{array}$ & $\begin{array}{c}-0,001^{* * *} \\
(0,000)\end{array}$ \\
\hline Sexo (masculino omitido) & $\begin{array}{c}-0,352^{\star \star \star} \\
-0,003\end{array}$ & $\begin{array}{c}-0,404^{\star \star \star} \\
-0,003\end{array}$ & $\begin{array}{c}-0,326^{\star \star \star} \\
(0,004)\end{array}$ & $\begin{array}{c}-0,414^{\star \star \star} \\
(0,004)\end{array}$ & $\begin{array}{c}-0,345^{\star \star \star} \\
-0,01\end{array}$ & $\begin{array}{c}-0,407^{\star \star \star} \\
-0,007\end{array}$ & $\begin{array}{c}-0,345^{\star \star \star} \\
(0,009)\end{array}$ & $\begin{array}{c}-0,430^{\star \star \star *} \\
(0,007)\end{array}$ \\
\hline \multicolumn{9}{|l|}{ Cor (branca omitida) } \\
\hline Preta & \begin{tabular}{|c|}
$-0,479^{\star \star \star}$ \\
$-0,006$
\end{tabular} & \begin{tabular}{|c|}
$-0,174^{\star \star *}$ \\
$-0,005$
\end{tabular} & $\begin{array}{c}-0,373^{\star \star *} \\
(0,007)\end{array}$ & $\begin{array}{c}-0,175^{\star * *} \\
(0,004)\end{array}$ & $\begin{array}{c}-0,597^{* * *} \\
-0,015\end{array}$ & $\begin{array}{c}-0,230^{\star * *} \\
-0,012\end{array}$ & $\begin{array}{c}-0,459^{* \star *} \\
(0,015)\end{array}$ & $\begin{array}{c}-0,164^{* * *} \\
(0,010)\end{array}$ \\
\hline Parda & $\begin{array}{c}-0,543^{\star \star \star} \\
-0,003\end{array}$ & \begin{tabular}{|c|}
$-0,227^{\star \star \star}$ \\
$-0,003$
\end{tabular} & $\begin{array}{c}-0,410^{\star \star \star} \\
(0,004)\end{array}$ & $\begin{array}{c}-0,163^{\star \star \star} \\
(0,003)\end{array}$ & $\begin{array}{l}-0,573 \\
-0,009\end{array}$ & $\begin{array}{c}-0,215^{\star \star \star} \\
-0,007\end{array}$ & $\begin{array}{c}-0,487^{\star \star \star} \\
(0,008)\end{array}$ & $\begin{array}{c}-0,156^{* * *} \\
(0,006)\end{array}$ \\
\hline \multicolumn{9}{|l|}{$\begin{array}{l}\text { Nível de instrução ( sem instrução } \\
\text { e fundamental incompleto }\end{array}$} \\
\hline $\begin{array}{l}\text { Fundamental completo e médio } \\
\text { incompleto }\end{array}$ & & $\begin{array}{c}0,381^{* * *} \\
-0,003\end{array}$ & & $\begin{array}{c}0,223^{\star * *} \\
(0,003)\end{array}$ & & $\begin{array}{c}0,383^{\star * *} \\
-0,009\end{array}$ & & $\begin{array}{c}0,214^{* * *} \\
(0,007)\end{array}$ \\
\hline $\begin{array}{l}\text { Médio completo e superior } \\
\text { incompleto }\end{array}$ & & $\begin{array}{c}0,925^{\star \star \star} \\
(0,003)\end{array}$ & & $\begin{array}{c}0,498^{\star \star \star} \\
(0,003)\end{array}$ & & $\begin{array}{c}0,938^{\star \star \star} \\
(0,009)\end{array}$ & & $\begin{array}{c}0,495^{\star * *} \\
(0,008)\end{array}$ \\
\hline Superior completo & & $\begin{array}{c}1,488^{\star * *} \\
(0,010)\end{array}$ & & $\begin{array}{c}1,193^{\star \star *} \\
(0,011)\end{array}$ & & $\begin{array}{l}1,707^{\star \star \star} \\
(0,018)\end{array}$ & & $\begin{array}{c}1,338^{\star * *} \\
(0,013)\end{array}$ \\
\hline $\begin{array}{l}\text { Vive rem região metropolitana? } \\
\text { (não omitido) }\end{array}$ & & \begin{tabular}{|c|}
$0,201^{\star \star *}$ \\
$(0,003)$
\end{tabular} & & $\begin{array}{c}0,192^{\star \star \star} \\
(0,005)\end{array}$ & & $\begin{array}{c}0,258^{\star \star \star} \\
(0,007)\end{array}$ & & $\begin{array}{c}0,175^{\star * *} \\
(0,006)\end{array}$ \\
\hline \multicolumn{9}{|l|}{$\begin{array}{l}\text { Região de residência (Nordeste } \\
\text { omitida) }\end{array}$} \\
\hline Norte & & $\begin{array}{l}-0,013 \\
(0,011)\end{array}$ & & $\begin{array}{c}0,148^{* \star *} \\
(0,009)\end{array}$ & & $\begin{array}{c}0,301^{\star * *} \\
(0,014)\end{array}$ & & $\begin{array}{c}0,234^{\star * *} \\
(0,015)\end{array}$ \\
\hline Sudeste & & $\begin{array}{c}0,267^{\star \star \star} \\
(0,004)\end{array}$ & & $\begin{array}{c}0,208^{\star \star \star} \\
(0,004)\end{array}$ & & $\begin{array}{c}0,419^{\star \star \star} \\
(0,009)\end{array}$ & & $\begin{array}{c}0,298^{* \star *} \\
(0,008)\end{array}$ \\
\hline Sul & & $\begin{array}{c}-0,016^{\star \star *} \\
(0,008)\end{array}$ & & $\begin{array}{c}0,027^{\star \star \star} \\
(0,011)\end{array}$ & & $\begin{array}{c}0,272^{\star \star \star} \\
(0,011)\end{array}$ & & $\begin{array}{c}0,213^{* \star \star} \\
(0,012)\end{array}$ \\
\hline Centro-Oeste & & $\begin{array}{c}-0,276^{\star * *} \\
(0,018)\end{array}$ & & $\begin{array}{c}0,031 \\
(0,019)\end{array}$ & & $\begin{array}{c}0,245^{\star \star *} \\
(0,014)\end{array}$ & & $\begin{array}{c}0,280^{* * *} \\
(0,036)\end{array}$ \\
\hline $\begin{array}{l}\text { Vive em região urbana ou rural? } \\
\text { (urbana omitido) }\end{array}$ & & $\begin{array}{c}-0,278^{* * *} \\
(0,003)\end{array}$ & & $\begin{array}{c}-0,206^{* * *} \\
(0,004)\end{array}$ & & $\begin{array}{c}-0,253^{* \star *} \\
(0,009)\end{array}$ & & $\begin{array}{c}0,221^{* * *} \\
(0,010)\end{array}$ \\
\hline $\begin{array}{l}\text { Trabalha no Setor Informal? (não } \\
\text { omitido) }\end{array}$ & & \begin{tabular}{|c|}
$-0,355^{\star \star *}$ \\
$(0,002)$
\end{tabular} & & $\begin{array}{c}-0,341^{\star * *} \\
(0,003)\end{array}$ & & $\begin{array}{c}-0,354^{* \star *} \\
(0,007)\end{array}$ & & $\begin{array}{c}-0,355^{\star \star \star} \\
(0,006)\end{array}$ \\
\hline $\begin{array}{l}\text { Média de Horas trabalhadas por } \\
\text { mês }\end{array}$ & & $\begin{array}{c}0,002^{\star \star \star} \\
(0,000)\end{array}$ & & $\begin{array}{c}0,002^{\star \star *} \\
(0,000)\end{array}$ & & $\begin{array}{c}0,002^{\star \star \star} \\
(0,000)\end{array}$ & & $\begin{array}{c}0,002^{* \star *} \\
(0,000)\end{array}$ \\
\hline$?_{1}$ & $\begin{array}{c}4,748^{\star \star \star} \\
(0,050)\end{array}$ & $\begin{array}{c}5,964^{\star \star \star} \\
(0,177)\end{array}$ & $\begin{array}{c}6,947^{\star \star \star} \\
(0,243)\end{array}$ & $\begin{array}{c}3,594^{\star \star \star} \\
(0,242)\end{array}$ & & & & \\
\hline$? 2$ & & & & & $\begin{array}{c}3,596 \\
(2,462)\end{array}$ & $\begin{array}{c}27,997^{\star \star \star} \\
(1,665)\end{array}$ & $\begin{array}{c}24,524^{\star \star \star} \\
(5,599)\end{array}$ & $\begin{array}{c}8,118^{* \star \star} \\
(2,680)\end{array}$ \\
\hline Constante & $\begin{array}{c}3,490^{\star \star \star} \\
(0,030)\end{array}$ & $\begin{array}{c}2,492^{\star \star *} \\
(0,061)\end{array}$ & $\begin{array}{c}4,010^{\star \star \star} \\
(0,084)\end{array}$ & $\begin{array}{c}3,975^{\star * *} \\
(0,076)\end{array}$ & $\begin{array}{c}4,947^{\star \star \star} \\
(0,118)\end{array}$ & $\begin{array}{c}3,344^{\star \star *} \\
(0,086)\end{array}$ & $\begin{array}{c}4,985^{\star * *} \\
(0,279)\end{array}$ & $\begin{array}{c}4,715^{\star * *} \\
(0,316)\end{array}$ \\
\hline Observações & 509.508 & 509.508 & 537.218 & 537.218 & 67.211 & 67.211 & 89.505 & 89.505 \\
\hline$R^{2}$ & 0,135 & 0.484 & 0,188 & 0,485 & 0,104 & 0,491 & 0,142 & 0,497 \\
\hline Prob> F & 0,000 & 0,000 & 0,000 & 0,000 & 0,000 & 0,000 & 0,000 & 0,000 \\
\hline
\end{tabular}

Fonte: Elaboração própria a partir dos resultados das estimativas.

Nota: ** Significativo a $1 \%,{ }^{* *}$ Significatio a $5 \%$. Erro-padrão entre parênteses.

$\lambda_{1}$ Razão inversa de Millis para migrante; $\lambda_{2}$ Razão inversa de Millis para migrante de retorno. 
Como visto na Tabela 5, o efeito da escolaridade para os rendimentos de migrantes e migrantes de retorno caiu entre 2000 e 2010. Se, em 2000, ter o Ensino Médio completo ou Fundamental incompleto em comparação a não ter instrução ou apenas o Fundamental incompleto aumentava em $152 \%$ o rendimento no trabalho principal dos migrantes, em 2010, esse percentual caiu para aproximadamente $65 \%$, redução bastante expressiva, indicando a expressiva diminuição do retorno à educação formal.

Os diferenciais de rendimentos para residentes em regiões metropolitanas e/ou urbanas em comparação a residentes em regiões não metropolitanas e rurais também caíram. O efeito negativo sobre o rendimento de um trabalhador migrante estar alocado no setor informal em comparação ao formal se reduz no período, porém para o migrante de retorno praticamente não houve alteração.

Em suma, migrantes e migrantes de retorno são, como aponta a literatura, positivamente selecionados. O efeito da idade sobre o rendimento se mostra positivo, ainda que com redução no período, assim como os diferencias de rendimento por cor. $\mathrm{O}$ diferencial de rendimento por gênero também diminuiu entre 2000 e 2010, mas em menor magnitude.

\section{Considerações finais}

O processo migratório é parte integrante da decisão de entrada no mercado de trabalho. Boa parte das pessoas que migra o faz buscando condições de trabalho (rendimento, carreira, setor, benefícios trabalhistas, entre outros) mais favoráveis do que as presentes em seu local de origem. Este trabalho é, portanto, mais uma evidência desse processo.

Os indivíduos que migram contam com características observadas e não observadas que os diferenciam no mercado de trabalho quando comparados aos residentes. Por essa razão, as estimativas apresentadas neste artigo mostram que migrantes e migrantes de retorno são positivamente selecionados no país, ou seja, apresentam habilidades não observadas que aumentam os rendimentos. Além disso, os migrantes são também positivamente selecionados com relação aos atributos observáveis e, por achados deste trabalho, conclui-se que os migrantes recebem, em média, mais que os não migrantes.

Outro resultado importante deste estudo diz respeito à migração de retorno, pois é um fenômeno que vem crescendo nos últimos anos no Brasil. Ainda que, no período intercensitário, tal processo tenha contribuído para ampliar a divergência de renda entre as regiões, como apontado por Mayr e Peri (2008), um braindrain pode vir a se tornar um braingain. Assim, os formuladores de políticas devem ficar atentos a esse fenômeno no intuito de aproveitar as oportunidades positivas de implementar políticas, incentivando o retorno daqueles que migraram e pretendem voltar ao local de origem, porque, certamente, estão mais capacitados depois da experiência de viver e trabalhar em outra localidade, podendo contribuir para melhorar o bem-estar nos locais de origem (Gama, 2012). 
Tabela 6 - Resultados das estimações de rendimentos com inclusão da razão inversa de Mills para os anos 2000 e 2010 - Comparação entre migrantes e migrantes de retorno

\begin{tabular}{|c|c|c|c|c|c|c|c|c|}
\hline \multicolumn{9}{|c|}{ Estimativas por MQO - Variável dependente: logaritmo do rendimento mensal } \\
\hline \multirow[b]{3}{*}{ VARIÁVEIS } & \multicolumn{4}{|c|}{ Sem Migrantes de Retorno } & \multicolumn{4}{|c|}{ Sem Migrantes de não Retorno } \\
\hline & \multicolumn{2}{|c|}{2000} & \multicolumn{2}{|c|}{2010} & \multicolumn{2}{|c|}{2000} & \multicolumn{2}{|c|}{2010} \\
\hline & (1) & (2) & (3) & (4) & $(5)$ & (6) & (7) & (8) \\
\hline Migrante (não migrante omitido) & $\begin{array}{l}0,028^{\star \star \star} \\
(0,002)\end{array}$ & $\begin{array}{c}0,040^{\star \star *} \\
(0,001)\end{array}$ & $\begin{array}{c}0,103^{\star * *} \\
(0,002)\end{array}$ & $\begin{array}{c}0,099^{\star * \star} \\
(0,001)\end{array}$ & & & & \\
\hline $\begin{array}{l}\text { Migrante de Retorno (Não } \\
\text { migrante omitido) }\end{array}$ & & & & & $\begin{array}{c}-0,033^{* * *} \\
(0,004)\end{array}$ & $\begin{array}{c}0,005 \\
(0,003)\end{array}$ & $\begin{array}{l}0,080^{* * *} \\
(0,004)\end{array}$ & $\begin{array}{c}0,075^{* * *} \\
(0,003)\end{array}$ \\
\hline Idade & $\begin{array}{c}0,134^{* * *} \\
(0,000)\end{array}$ & $\begin{array}{c}0,118^{* * *} \\
(0,001)\end{array}$ & $\begin{array}{c}0,108^{* * *} \\
(0,001)\end{array}$ & $\begin{array}{c}0,074^{\star * *} \\
(0,001)\end{array}$ & $\begin{array}{l}0,077^{\star \star \star} \\
(0,001)\end{array}$ & $\begin{array}{l}0,096^{\star * *} \\
(0,001)\end{array}$ & $\begin{array}{c}0,073^{\star \star \star} \\
(0,002)\end{array}$ & $\begin{array}{l}0,054^{* * *} \\
(0,001)\end{array}$ \\
\hline Idade ao quadrado & $\begin{array}{c}-0,001^{* * *} \\
(0,000)\end{array}$ & $\begin{array}{c}-0,001^{* * *} \\
(0,000)\end{array}$ & $\begin{array}{c}-0,001^{\star \star *} \\
(0,000)\end{array}$ & $\begin{array}{c}-0,001^{* * *} \\
(0,000)\end{array}$ & $\begin{array}{c}-0,001^{* \star *} \\
(0,000)\end{array}$ & $\begin{array}{c}-0,001^{* * *} \\
(0,000)\end{array}$ & $\begin{array}{c}-0,001^{* * *} \\
(0,000)\end{array}$ & $\begin{array}{c}-0,000^{* \star *} \\
(0,000)\end{array}$ \\
\hline Sexo (masculino omitido) & $\begin{array}{c}-0,301^{\star \star \star} \\
(0,001)\end{array}$ & $\begin{array}{c}-0,386^{\star * *} \\
(0,001)\end{array}$ & $\begin{array}{c}-0,258^{\star \star *} \\
(0,001)\end{array}$ & $\begin{array}{c}-0,368^{\star \star \star} \\
(0,001)\end{array}$ & $\begin{array}{c}-0,372^{\star \star *} \\
(0,001)\end{array}$ & $\begin{array}{c}-0,407^{\star * *} \\
(0,001)\end{array}$ & $\begin{array}{c}-0,280^{\star \star \star} \\
(0,001)\end{array}$ & $\begin{array}{c}-0,386^{\star \star \star} \\
(0,001)\end{array}$ \\
\hline \multicolumn{9}{|l|}{ Cor (branca omitida) } \\
\hline Preta & $\begin{array}{c}-0,491^{\star * \star} \\
(0,002)\end{array}$ & $\begin{array}{c}-0,218^{\star * *} \\
(0,002)\end{array}$ & $\begin{array}{c}-0,349^{\star \star *} \\
(0,002)\end{array}$ & $\begin{array}{c}-0,193^{\star * \star} \\
(0,001)\end{array}$ & $\begin{array}{c}-0,609^{\star \star \star} \\
(0,002)\end{array}$ & $\begin{array}{c}-0,275^{\star * *} \\
(0,001)\end{array}$ & $\begin{array}{c}-0,431^{\star * \star} \\
(0,002)\end{array}$ & $\begin{array}{c}-0,201^{\star \star \star} \\
(0,001)\end{array}$ \\
\hline Parda & $\begin{array}{c}-0,566^{* * *} \\
(0,001)\end{array}$ & $\begin{array}{c}-0,239^{* \star \star} \\
(0,001)\end{array}$ & $\begin{array}{c}-0,387^{\star \star *} \\
(0,001)\end{array}$ & $\begin{array}{c}0,170^{* * *} \\
(0,001)\end{array}$ & $\begin{array}{c}-0,578^{\star \star *} \\
(0,001)\end{array}$ & $\begin{array}{c}-0,235^{\star * *} \\
(0,001)\end{array}$ & $\begin{array}{c}-0,453^{\star * \star} \\
(0,001)\end{array}$ & $\begin{array}{c}-0,172^{\star \star \star} \\
(0,001)\end{array}$ \\
\hline \multicolumn{9}{|l|}{$\begin{array}{l}\text { Nível de instrução ( sem } \\
\text { instrução e fundamenteal } \\
\text { incompleto omitido) }\end{array}$} \\
\hline $\begin{array}{l}\text { Fundamental completo e médio } \\
\text { incompleto }\end{array}$ & & $\begin{array}{c}0,361^{* * *} \\
(0,001)\end{array}$ & & $\begin{array}{c}0,239^{* * *} \\
(0,001)\end{array}$ & & $\begin{array}{l}0,372^{* * *} \\
(0,001)\end{array}$ & & $\begin{array}{l}0,244^{\star \star \star} \\
(0,001)\end{array}$ \\
\hline $\begin{array}{l}\text { Médio completo e superior } \\
\text { incompleto }\end{array}$ & & $\begin{array}{c}0,854^{* * *} \\
(0,001)\end{array}$ & & $\begin{array}{c}0,468^{\star \star *} \\
(0,001)\end{array}$ & & $\begin{array}{c}0,897^{\star \star \star *} \\
(0,001)\end{array}$ & & $\begin{array}{c}0,485^{\star \star *} \\
(0,001)\end{array}$ \\
\hline $\begin{array}{l}\text { Médio completo e superior } \\
\text { incompleto }\end{array}$ & & $\begin{array}{l}1,444^{* * *} \\
(0,004)\end{array}$ & & $\begin{array}{c}1,113^{\star \star \star} \\
(0,003)\end{array}$ & & $\begin{array}{l}1,612^{* * *} \\
(0,002)\end{array}$ & & $\begin{array}{l}1,209^{\star \star *} \\
(0,002)\end{array}$ \\
\hline $\begin{array}{l}\text { Vive rem região metropolitana? } \\
\text { (não omitido) }\end{array}$ & & $\begin{array}{c}0,273^{\star * *} \\
(0,001)\end{array}$ & & $\begin{array}{l}0,231^{* * *} \\
(0,001)\end{array}$ & & $\begin{array}{l}0,260^{\star * *} \\
(0,001)\end{array}$ & & $\begin{array}{l}0,188^{* \star *} \\
(0,001)\end{array}$ \\
\hline \multicolumn{9}{|l|}{$\begin{array}{l}\text { Região de residência (Nordeste } \\
\text { omitida) }\end{array}$} \\
\hline Norte & & $\begin{array}{c}0,040^{* * *} \\
(0,005)\end{array}$ & & $\begin{array}{c}0,164^{* * *} \\
(0,003)\end{array}$ & & $\begin{array}{l}0,292^{* * *} \\
(0,002)\end{array}$ & & $\begin{array}{l}0,232^{* \star *} \\
(0,002)\end{array}$ \\
\hline Sudeste & & $\begin{array}{l}0,369^{* \star *} \\
(0,001)\end{array}$ & & $\begin{array}{l}0,275^{\star \star \star} \\
(0,001)\end{array}$ & & $\begin{array}{l}0,455^{\star \star \star} \\
(0,001)\end{array}$ & & $\begin{array}{c}0,308^{\star \star *} \\
(0,001)\end{array}$ \\
\hline Sul & & $\begin{array}{c}0,104^{* * *} \\
(0,004)\end{array}$ & & $\begin{array}{l}0,147^{\star \star \star} \\
(0,004)\end{array}$ & & $\begin{array}{l}0,323^{\star \star \star} \\
(0,001)\end{array}$ & & $\begin{array}{l}0,264^{* \star *} \\
(0,002)\end{array}$ \\
\hline Centro-Oeste & & $\begin{array}{c}-0,137^{* * *} \\
(0,009)\end{array}$ & & $\begin{array}{l}0,171^{* \star *} \\
(0,006)\end{array}$ & & $\begin{array}{l}0,315^{\star \star \star} \\
(0,002)\end{array}$ & & $\begin{array}{l}0,319^{* * *} \\
(0,006)\end{array}$ \\
\hline $\begin{array}{l}\text { Vive em região urbana ou rural? } \\
\text { (urbana omitido) }\end{array}$ & & $\begin{array}{c}-0,263^{* * *} \\
(0,001)\end{array}$ & & $\begin{array}{c}-0,244^{* * *} \\
(0,001)\end{array}$ & & $\begin{array}{c}-0,258^{* * *} \\
(0,001)\end{array}$ & & $\begin{array}{c}-0,254^{* * *} \\
(0,001)\end{array}$ \\
\hline $\begin{array}{l}\text { Trabalha no Setor Informal? } \\
\text { (não omitido) }\end{array}$ & & $\begin{array}{c}-0,360^{* * *} \\
(0,001)\end{array}$ & & $\begin{array}{c}-0,346^{* * *} \\
(0,001)\end{array}$ & & $\begin{array}{c}-0,363^{* * *} \\
(0,001)\end{array}$ & & $\begin{array}{c}-0,347^{\star \star \star} \\
(0,001)\end{array}$ \\
\hline $\begin{array}{l}\text { Média de Horas trabalhadas por } \\
\text { mês }\end{array}$ & & $\begin{array}{c}0,002^{* * *} \\
(0,000)\end{array}$ & & $\begin{array}{l}0,002^{* \star *} \\
(0,000)\end{array}$ & & $\begin{array}{l}0,002^{* * *} \\
(0,000)\end{array}$ & & $\begin{array}{l}0,002^{* \star *} \\
(0,000)\end{array}$ \\
\hline$?_{1}$ & $\begin{array}{l}5,306^{\star \star *} \\
(0,026)\end{array}$ & $\begin{array}{l}5,791^{* \star *} \\
(0,095)\end{array}$ & $\begin{array}{c}7,767^{* * *} \\
(0,099)\end{array}$ & $\begin{array}{l}3,425^{\star \star \star} \\
(0,089)\end{array}$ & & & & \\
\hline$?_{2}$ & & & & & $\begin{array}{c}-7,940^{* * *} \\
(0,385)\end{array}$ & $\begin{array}{c}26,014^{\star * *} \\
(0,451)\end{array}$ & $\begin{array}{c}25,078^{* * *} \\
(1,416)\end{array}$ & $\begin{array}{l}8,052^{* * *} \\
(0,519)\end{array}$ \\
\hline Constante & $\begin{array}{l}3,311^{\star * *} \\
(0,011)\end{array}$ & $\begin{array}{c}2,408^{\star \star *} \\
(0,031)\end{array}$ & $\begin{array}{c}3,902^{* * *} \\
(0,031)\end{array}$ & $\begin{array}{c}4,097^{* * *} \\
(0,026)\end{array}$ & $\begin{array}{l}5,390^{* * *} \\
(0,016)\end{array}$ & $\begin{array}{l}3,249^{* \star *} \\
(0,018)\end{array}$ & $\begin{array}{l}5,165^{\star * *} \\
(0,061)\end{array}$ & $\begin{array}{c}4,726^{* * *} \\
(0,023)\end{array}$ \\
\hline Observações & 5.014 .787 & 5.014 .787 & 6.261 .641 & 6.261 .641 & 4.572 .490 & 4.572 .490 & 5.813 .928 & 5.813 .928 \\
\hline $\mathrm{R}^{2}$ & 0,137 & 0,498 & 0,162 & 0,471 & 0,113 & 0,495 & 0,118 & 0,466 \\
\hline Prob $>F$ & 0,000 & 0,000 & 0,000 & 0,000 & 0,000 & 0,000 & 0,000 & 0,000 \\
\hline
\end{tabular}

Fonte: Elaboração própria a partir dos resultados das estimativas.

Nota: ${ }^{* *}$ Significativo a $1 \%$. Erro-padrão entre parênteses.

$\lambda_{1}$ Razão inversa de Millis para migrante; $\lambda_{2}$ Razão inversa de Millis para migrante de retorno. 
Notas

1 Como exemplos de características não observáveis, podemos destacar as habilidades e a produtividade de um indivíduo.

2 Foram também excluídos os indivíduos que eram empregados domésticos, parentes de empregados domésticos e pensionistas, pela possibilidade de dupla contagem.

3 Quando o peso amostral é utilizado em uma estimativa, implica um cálculo da matriz de variância-covariância robusto, ou seja, é reportado erro padrão robusto.

\section{Referências}

BARROS, R. P.; FRANCO, S.; MENDONÇA, R. Discriminação e segmentação no mercado de trabalho e desigualdade de renda no Brasil. Texto para discussão IPEA, Rio de Janeiro, n.1288, 2007.

BORJAS, G. J. Self-selection and the earnings of immigrants. The American Economic Review, v.77, n.4, p.531-53, 1987.

Immigrationand self-selection. NBER Working Paper, Cambridge, National Bureau of Economic Research, v.2566, 1988.

Labor economics. 3.ed. Irwin: McGraw-Hill, 2004.

COOPER, J. M. R. Migration and market wage risk. Journal of Regional Science, v.34, n.4, p.563-82, 1994.

CUNHA, J. M. P. da. A migração no começo do século 21 : continuidades e novidades trazidas pela PNAD 2004. Parcerias Estratégicas, Brasília, v.22, p.381-439, 2006.

CUNHA, J. M. P. da; BAENINGER, R. Cenários da migração no Brasil nos anos 90. Cadernos do CRH, Salvador, v.18, n.43, jan./abril. 2005.

DAHL, G. B. Mobility and the return to education: testing a Roy Model with multiple markets. RCER Working Paper, University of Rochester - Center for Economic Rese$\operatorname{arch}$ (RCER), 2002.

DUSTMANN, C.; GLITZ, A. Migration and education. Centre of Research and Analysis of Migration, Discussion Paper Series, n.5, 2011.

FREGUGLIA, R. S. Efeitos da migração sobre os salários no Brasil. 2007. Tese (Doutorado em Teoria Econômica) - Faculdade de Economia, Administração e Contabilidade, Universidade de São Paulo. São Paulo, 2007.

GAMA, L. C. D. O Programa Bolsa Família pode influenciar a decisão de migrar? Uma análise para o estado de Minas Gerais. In: SEMINÁRIO SOBRE A ECONOMIA MINEIRA, 15., 2012, Diamantina. Anais... Belo Horizonte: Cedeplar, 2012.

HECKMAN, J. J. SampleSelection Bias as a SpecificationError. Econometrica, v.47, n.1, p.153-61, 1979.

MAYR, K.; PERI, G. Return migration as a channel of brain gain. Center for Research and Analysis of Migration. Discussion Paper Series, n.4, 2008.

RODRÍGUEZ-POSE, A.; TSELIOS, V. Returns to migration, education, and externalities in the European Union. Working Paper, Fondazione Eni Enrico Mattei, 2010. 
ROOTH, D. O.; SAARELA, J. Selection in migration and return migration: evidence from micro data. Economics Letters, v.94, n.1, p.90-5, 2007.

SAHOTA, G. S. An economic analysis of internal migration in Brazil. Journal of Political Economy, v.76, n.2, p.218-45, 1968.

SIQUEIRA, L. B. O; MAGALHAES, A. M.; SILVEIRA NETO, R. M. Migração de retorno e migração progressiva no Brasil: evidências a partir do critério de data fixa do Censo de 2000. In: ENCONTRO NACIONAL DA ASSOCIAÇÃO BRASILEIRA DE ESTUdOS REGIONAIS E URBANOS, 7., 2009, São Paulo. Anais... São Paulo: ABER, 2009.

SJAASTAD, L. A. The costs and returns of human migration. Journal of Political Economy, v.70, n.5, p.80-93, 1962.

RESUMO - Este trabalho investiga as alterações nos diferenciais de rendimentos entre migrantes, migrantes de retorno e não migrantes, entre 2000 e 2010 , no Brasil. São utilizados dados do Censo Demográfico. Entre os principais resultados, destaca-se que ser homem, jovem e escolarizado eleva à probabilidade de migrar e retornar. Migrantes e migrantes de retorno são mais bem remunerados que não migrantes. A situação dos trabalhadores melhorou no período, pois houve elevação dos rendimentos e diminuição das desigualdades regionais de renda, tendo a migração contribuindo para tal.

PALAVRAS-CHAVE: Migração, Trabalho, Rendimentos.

ABSTRACT - This work investigates how economic changes, from 2000 to 2010, in Brazil have affected the earning gap of migrants, return migrants and non-migrants. We use data from Censuses. Amongst the main results we found that being male, young and schooled elevates the probability of migrate and return in 2000 and 2010. Migrants and return migrants are better remunerated than non-migrants. The situation of workers improved in the period, given the growth of income and the decrease in income inequality, and migration appears to be connected with these changes.

KEYWORDS: Migration, Labor, Earnings.

Luiz Carlos Day Gama é doutorando em Economia pelo Centro de Desenvolvimento e Planejamento Regional da Universidade Federal de Minas Gerais (Cedeplar/UFMG). @-lcdgama@gmail.com

Ana Flávia Machado é professora associada do Departamento de Ciências Econômicas da Universidade Federal de Minas Gerais (UFMG). Bolsista de Produtividade do CNPq. @- afmachad@cedeplar.ufmg.br

Recebido em 16.6.2014 e aceito em 15.7.2014.

I, II Universidade Federal de Minas Gerais. Belo Horizonte/MG, Brasil. 